\title{
Effects of wheat-flour and oat mill fractions on jejunal flow, starch degradation and absorption of glucose over an isolated loop of jejunum in pigs
}

\author{
BY HELLE N. JOHANSEN ${ }^{1,2}$ AND K. E. BACH KNUDSEN ${ }^{1}$ \\ ${ }^{1}$ National Institute of Animal Science, Department of Animal Physiology and Biochemistry, \\ Research Centre Foulum, PO Box 39, DK-8830 Tjele, Denmark \\ ${ }^{2}$ Research Department of Human Nutrition, The Royal Veterinary and Agricultural University, \\ Rolighedsvej 25, DK-1870 Frederiksberg C, Copenhagen, Denmark
}

(Received 21 December 1992 - Revised 1 November 1993 - Accepted 3 December 1993)

\begin{abstract}
The effect of cereal-based diets varying in dietary fibre (DF) on gastric emptying and glucose absorption over an isolated loop of jejunum was studied in four pigs fitted with two sets of re-entrant cannulas. The pigs were fed on either a wheat-flour diet or three diets based on oat flour (endosperm), rolled oats or oat bran containing different amounts of soluble DF. Mean transit time (MTT) of liquid estimated from the output from the first jejunal cannula was significantly higher with the two diets having the highest DF content, but MTT of dry matter (DM), starch, xylose and neutral non-starch polysaccharides (nNSP) was not correlated directly to the DF content of the diet. DF had a stimulatory effect on secretion of gastrointestinal juices, but the effect was not linearly correlated with the DF content of the diet. Starch was significantly degraded in digesta collected within $30 \mathrm{~min}$ after feeding with maltooligosaccharides accounting for $140-147 \mathrm{~g} / \mathrm{kg}$ total starch. The degradation was more extensive with higher DF and lower starch content of the diet. However, taking into account the differences in jejunal flow, the amount of malto-oligosaccharides available for absorption in the first $0.5 \mathrm{~h}$ decreased with higher levels of DF in the oat-based diets. The absorption of glucose from the isolated loop was 18-34 g/m intestine over an $8 \mathrm{~h}$ period with no significant differences between diets. This corresponded to a non-significant decrease in recovery of starch from 0.91 to 0.82 with increasing levels of DF and decreasing levels of starch in the diet. This suggests that the capacity for absorption of large doses of starch entering the proximal small intestine after ingestion of a carbohydrate-rich cereal-based diet has a major influence on the absorption at this site. Consequently any effect of DF on glucose absorption may be exerted either through the rate of gastric emptying or by impaired rate of absorption more distal in the small intestine and not by displacement of the site for starch absorption.
\end{abstract}

Soluble dietary fibre: Jejunal flow: Glucose absorption: Starch degradation

It is well documented that an increased intake of dietary fibre (DF; non-starch polysaccharides (NSP) + lignin), and soluble DF in particular, has beneficial health effects. Several clinical studies with hypercholesterolaemic, diabetic and normal subjects and animal studies with rats and pigs have clearly shown that oat bran, a rich source of soluble $\mathrm{DF}$ in the form of mixed-linked $(1 \rightarrow 3)(1 \rightarrow 4)-\beta$-D-glucans $(\beta$-glucan; Wood \& Fulcher, 1978 ), has a significant potential for improving carbohydrate metabolism and lowering blood cholesterol levels (for example, see Chen \& Anderson, 1986; Wood et al. 1990). The mechanism behind the hypoglycaemic effect of oat bran is uncertain, but model experiments with purified $\beta$-glucan (oat gum) suggest that luminal viscosity plays an important role either by delaying gastric emptying and/or reducing the rate of glucose absorption in 
the small intestine (Lund et al. 1989; Wood et al. 1990). Although conflicting results appear, it is generally believed that soluble fibres above a certain concentration attenuate glucose transport across the intestinal mucosa (Blackburn \& Johnson, 1983; Rainbird et al. 1984) and that viscosity is a key factor (Lund et al. 1989; Roberts et al. 1991). The influence of soluble DF on the rate of gastric emptying is less clear. Results appearing in the literature are conflicting, most probably due to differences in experimental conditions, e.g. whether liquid or solid meals are studied. The emptying of solid components of the meal is presumably the most important in relation to rate of carbohydrate absorption since they contain most of the starch ingested (Rainbird \& Low, 1986a).

It has previously been shown, by perfusion of sugar solutions at a constant flow-rate, that a soluble DF isolate in the form of guar gum (a galactomannan polysaccharide) reduces the net absorption in vivo of glucose and maltose from an isolated loop of the upper jejunum of pigs fitted with two sets of re-entrant cannulas (Rainbird et al. 1984). To determine whether there is a similar effect on glucose absorption from cereal diets naturally rich in soluble DF, such as oats, we have used a modification of the technique used by Rainbird et al. (1984). The aim was to study simultaneously the effect of cereal-based diets varying in soluble DF on flow from the stomach to the upper small intestine and on absorption of G1 in an isolated loop of jejunum when diurnal variations of digesta flow also were adopted. Variation in content of soluble DF was obtained by formulating diets of white wheat flour, oat flour (central endosperm), rolled oats and oat bran. On the basis of the studies with isolated DF sources it was expected that higher amounts of DF in these diets could lead to slowed gastric emptying. On the other hand, if the general observation of a slower glucose absorption is caused by a shift in site of absorption as suggested by Jenkins et al. (1987), higher amounts of soluble DF in the diet were expected to lead to a reduction in the amount of glucose absorbed in the isolated loop of the proximal jejunum. Since absorption of glucose from starch-based diets involves degradation by $\alpha$-amylase (EC 3.2.1.1) the extent of starch degradation in digesta collected within the first $0.5 \mathrm{~h}$ after feeding was measured.

\section{EXPERIMENTAL}

\section{Animals and surgery}

Four crossbred castrated male pigs of approximately $30 \mathrm{~kg}$ initial body weight were used in the experiment. All pigs were anaesthetized with halothane- $\mathrm{O}_{2}(0.5: 100, \mathrm{v} / \mathrm{v} ; 2.01 / \mathrm{min})$ and two sets of re-entrant cannulas were placed in the jejunum according to the procedure of Horszczaruk et al. (1974) following the description of Rainbird et al. (1984). The first set of re-entrant cannulas was placed approximately $1 \mathrm{~m}$ from the pylorus and the second set about $1.5 \mathrm{~m}$ distal to the first. This provided an isolated part of the jejunum through which perfusion could take place (Rainbird et al. 1984). After 10-14 d of recovery, experiments were carried out for four consecutive weeks. At the end of the experiment the pigs were killed and the distance between stomach and the first cannula, and the length of the intestinal loop were measured.

\section{Diets and feeding}

The four experimental diets were prepared from wheat flour (WF), oat flour (OF), rolled oats (RO) and oat bran (OB; Table 1). The pigs were fed on the diets for 1 week each in a $4 \times 4$ Latin Square design in three equal meals at $07.00,15.00$ and 22.00 hours. The total daily intake was $45 \mathrm{~g} / \mathrm{kg}$ body weight per $\mathrm{d}$ and the water intake was 2.5-3 times the amount of feed. The pigs' diets were changed over a $3 \mathrm{~d}$ period by gradually increasing the proportion of the following diet in the preceding diet. The first collection period took place 
Table 1. Ingredients, chemical composition and physical properties of experimental diets

\begin{tabular}{|c|c|c|c|c|}
\hline Diets... & WF & OF & RO & OB \\
\hline \multicolumn{5}{|l|}{ Ingredients $(\mathrm{g} / \mathrm{kg}$ diet) } \\
\hline Wheat flour & 812 & - & - & - \\
\hline Oat flour & - & 867 & - & - \\
\hline Rolled oats & - & - & 900 & - \\
\hline Oat bran & - & - & - & 943 \\
\hline Casein & 118 & 103 & 70 & 27 \\
\hline Soya-bean oil & 40 & - & - & - \\
\hline Vitamin-mineral mix* & 30 & 30 & 30 & 30 \\
\hline \multicolumn{5}{|c|}{ Chemical composition (g/kg DM) } \\
\hline Starch & 620 & 593 & 560 & 425 \\
\hline Protein $(\mathrm{N} \times 6.25)$ & 214 & 198 & 198 & 221 \\
\hline $\mathrm{HCl}$ fat & 62 & 74 & 90 & 100 \\
\hline Ash & 33 & 40 & 43 & 53 \\
\hline nNSP & 26 & 32 & 57 & 115 \\
\hline S-nNSP & 17 & 18 & 33 & 69 \\
\hline Xylose & 11 & 7 & 11 & 22 \\
\hline$\beta$-glucan & 2 & 19 & 36 & 80 \\
\hline Klason lignin & 5 & 6 & 9 & 19 \\
\hline Gross energy (MJ/kg DM) & $19 \cdot 39$ & $19 \cdot 43$ & 19.80 & $19 \cdot 95$ \\
\hline \multicolumn{5}{|l|}{ Physical properties } \\
\hline Viscosity (mPa.s) $†$ & 0.9 & $2 \cdot 3$ & 6.9 & 75 \\
\hline WHC (g water/g DM) & $2 \cdot 44$ & $2 \cdot 52$ & $\mathbf{3 . 0 7}$ & 3.83 \\
\hline Particles $<63 \mu \mathrm{m}(\%)_{+}^{+}$ & $46 \cdot 5$ & $71 \cdot 5$ & 52.5 & 6.0 \\
\hline Particles $>500 \mu \mathrm{m}(\%) \ddagger$ & 0.0 & 0.0 & 13.5 & $65 \cdot 0$ \\
\hline
\end{tabular}

nNSP, neutral non-starch polysaccharides; S-nNSP, soluble neutral non-starch polysaccharides; WHC, waterholding capacity.

* Provided (mg/kg diet): $\mathrm{Ca}_{2}\left(\mathrm{PO}_{4}\right)_{3} 17000, \mathrm{~K}_{2} \mathrm{PO}_{4} 5700, \mathrm{NaCl} 4000, \mathrm{CaCO}_{3} 2500, \mathrm{FeSO}_{4} .7 \mathrm{H}_{2} \mathrm{O} 212, \mathrm{ZnO} 85$, $\mathrm{MnO} 31, \mathrm{CuSO}_{4} .5 \mathrm{H}_{2} \mathrm{O} 68, \mathrm{KI} \mathrm{0.2,} \mathrm{Na}_{2} \mathrm{SeO}_{3} .5 \mathrm{H}_{2} \mathrm{O} 0.6$, retinyl acetate 1.27 , cholecalciferol 0.02 , $\alpha$-tocopherol 43 , menadione $1 \cdot 7$, riboflavin $3 \cdot 4$, pantothenic acid $8 \cdot 5$, cobalamin $0 \cdot 02$.

$\dagger$ At shear rate $45 / \mathrm{s}, 38^{\circ}$.

$\ddagger$ Particle size distribution in flours.

after $2 \mathrm{~d}$ on the new diet. On the day of digesta collection the pigs were placed in metabolism cages before the morning feeding and kept there during the $8 \mathrm{~h}$ collection period. Polyethylene glycol 4000 (PEG) was added as a water-soluble marker to the meal ( $6 \mathrm{~g}$ per meal). The collection procedure was repeated twice for each diet. The feed ration was generally consumed within $5 \mathrm{~min}$. In the periods between digesta collection the pigs were housed individually in $4 \mathrm{~m}^{2}$ smooth-walled pens with concrete floors.

\section{Collection and perfusion method}

The re-entrant cannulas were connected as shown in Fig. $1(a)$ for normal passage of digesta when the pigs were housed in the pens. During experimental periods the cannulas were disconnected as shown in Fig. 1(b) to allow collection of digesta from the first cannula, infusion of digesta and re-collection after perfusion through the isolated loop.

Initially the loop was rinsed with $500 \mathrm{ml}$ saline $(9 \cdot 1 \mathrm{~g} \mathrm{NaCl} / \mathrm{l})$. Perfusate collected in this period was discarded. After feeding, digesta were continuously collected on ice. At short intervals digesta were weighed and $100 \mathrm{~g} / \mathrm{kg}$ taken for analysis. The digesta were re-heated to body temperature $\left(38^{\circ}\right)$ and infused via a peristaltic pump into the isolated loop. Reheating was done by passing silicone tubing which connected the digesta container to the 

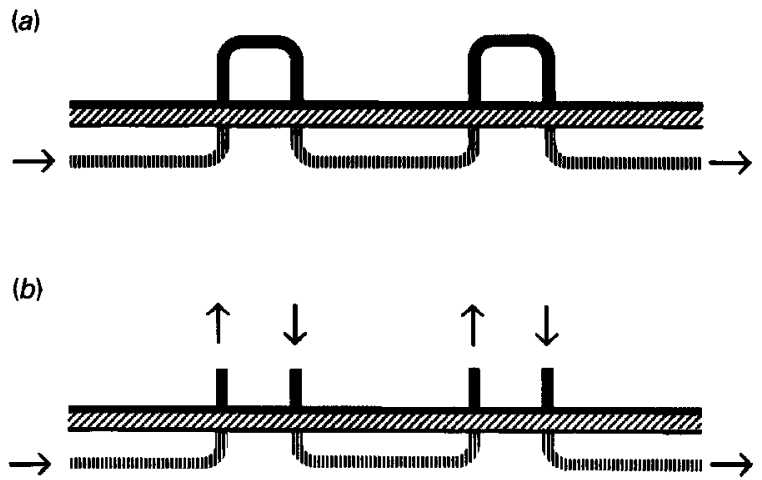

Fig. 1. Schematic diagram of flow in the jejunum of pigs fitted with two sets of re-entrant cannulas: (a) in periods between and $(b)$ during collection and perfusion. For details of diets and procedures, see Table 1 and pp. 300-302. (), Re-entrant cannula; (四), intestine; (囚), body wall.

re-entrant cannula through a water-bath. The flow-rate during perfusion was adapted to the flow from the first cannula. Collection and sampling of perfusate was performed as described previously. Finally, the remaining digesta were infused into the last cannula. A total of $500 \mathrm{ml}$ saline solution was used for rinsing collection bottles and the loop after perfusion.

For estimation of flow from the first cannula, digesta samples were pooled into six periods; $0-0.5,0 \cdot 5-1,1-2,2-3,3-5$ and $5-7 \cdot 5 \mathrm{~h}$ after feeding and frozen immediately after collection. Perfusion of digesta and rinsing of the loop after infusion of the last digesta was completed within $8 \mathrm{~h}$. The rinses were included in the last sample collected from the loop. The perfusates collected from the loop were pooled into three periods; $0-1,1-3$ and $3-8 \mathrm{~h}$ after feeding and the samples taken for analysis stored frozen at $-18^{\circ}$.

\section{Analytical methods}

All analyses were performed in duplicate. Analysis of PEG was performed on wet materials by the turbidimetric method of Hyden (1955). All other analyses were carried out on freezedried materials. Dry matter (DM) was determined by freeze-drying followed by drying at $105^{\circ}$ for $24 \mathrm{~h}$.

Protein $(\mathrm{N} \times 6.25)$ was determined by the Kjeldahl method using a Kjell-Foss 16210 autoanalyzer (Foss Electric A/S, Hillerød, Denmark) and gross energy was measured in a LECO AC 300 automated calorimeter system 789-500 (LECO, St Joseph, MI, USA). Ash was analysed according to the Association of Official Analytical Chemists (1975) and fat was extracted with diethyl ether after acid-hydrolysis (Stoldt, 1952). Starch was analysed enzymically, neutral NSP (nNSP) and their constituent sugars as alditol acetates by GLC, and Klason lignin gravimetrically as described in detail by Bach Knudsen et al. (1993). $\beta$ glucan was determined by the enzymic method (MegaZyme Pty. Ltd., North Rocks, NSW, Australia) of McCleary \& Glennie-Holmes (1985).

Malto-oligosaccharides were determined by high-performance anion-exchange chromatography (HPAEC) on a Dionex BioLC Model 4000i system and Ionchrom Pulsed Amperometric Detector. The chromatographic data system was an AI-450 chromatography Automation System (Dionex Corp., Sunnyvale, CA, USA). A CarboPac PA1, $4 \times 250 \mathrm{~mm}$ column equipped with a CarboPac PAl guard column, $3 \times 25 \mathrm{~mm}$ (Dionex Corp.), was used for the separation of malto-oligosaccharides. The sugars were eluted at a constant flow-rate of $0.8 \mathrm{ml} / \mathrm{min}$ with an isocratic elution of 
solution $\mathrm{A}(100 \mathrm{mM}-\mathrm{NaOH})$ for $5 \mathrm{~min}$ followed by a linear gradient for $15 \mathrm{~min}$ of $0-100 \%$ solution $\mathrm{B}(150 \mathrm{~mm}-\mathrm{NaOAc}+150 \mathrm{mM}-\mathrm{NaOH})$ with post-column addition of $300 \mathrm{~mm}-$ $\mathrm{NaOH}$ at a constant flow-rate of $0.8 \mathrm{ml} / \mathrm{min}$. Freeze-dried digesta $(100 \mathrm{mg})$ were extracted in $5 \mathrm{ml}$ aqueous ethanol $(800 \mathrm{ml} / \mathrm{l})$ for $1 \mathrm{~h}$ at $85^{\circ}$ with constant mixing. The extracted material was centrifuged at $14500 \mathrm{~g}$ for $10 \mathrm{~min}$ and the supernatant fraction transferred to a $10 \mathrm{ml}$ centrifuge tube. The residue was extracted with another $5 \mathrm{ml}$ aqueous ethanol, centrifuged and the supernatant fraction from the second extraction combined with the first extract. Finally, the extract was evaporated to dryness with $\mathrm{N}_{2}$ and left overnight in a desiccator containing $\mathrm{KOH}$. The dry sample was re-dissolved in water and filtered through a Millipore filter (pore size $5 \mu \mathrm{m}$ ) and diluted before analysis. Standard solutions $(10-100 \mu \mathrm{g} / \mathrm{ml})$ of glucose, sucrose, maltose and maltotriose, maltotetraose, maltopentaose and maltohexaose (Sigma Chemical Company, St Louis, MO, USA) were used for calibration.

Particle size distribution in flours was determined in an Augsburg Luftstrahl bolter using $32,63,125,250,500$ and $1000 \mu \mathrm{m}$ sieves. Sifting times for $20.0 \mathrm{~g}$ flour were $3 \mathrm{~min}$ for the $32 \mu \mathrm{m}$ sieve, $2 \mathrm{~min}$ for the $63 \mu \mathrm{m}$ sieve, $1 \mathrm{~min}$ for the $125 \mu \mathrm{m}$ sieve and $30 \mathrm{~s}$ for the 250,500 and $1000 \mu \mathrm{m}$ sieves.

Viscosity and water-holding capacity (WHC) of diets were measured after suspension of disc-milled diet in water $\left(100 \mathrm{~g} / \mathrm{kg}\right.$ ) for $1 \mathrm{~h}$ at $38^{\circ}$ with constant mixing followed by centrifugation at $12000 \mathrm{~g}$ for $20 \mathrm{~min}$. After weighing, sediment and supernatant fractions were separated and viscosity of the supernatant fraction was measured in a Brookfield DVII cone/plate viscometer at $38^{\circ}$. Absolute viscosity (mPa.s) is presented at $45 / \mathrm{s}$. The centrifuge tubes were turned upside down to drain off residual supernatant fraction for at least $1 \mathrm{~h}$ before weighing. The sediment was then dried in the centrifuge tubes in a vacuum oven at $50^{\circ}$ for $16 \mathrm{~h}$ and weighed again to calculate DM content in the sediment.

\section{Calculation and statistical analyses}

WHC (g water/g DM) was calculated as:

$$
\text { WHC }=\frac{\text { weight before drying }- \text { dry weight }}{\text { dry weight }} .
$$

The content of polysaccharide residues was calculated as anhydrosugars and all measurements of recovery and absorption were calculated either on the basis of the digesta content collected or relative to PEG, xylose or nNSP as markers. All results were standardized to a feed intake of $500 \mathrm{~g}$ dry feed and $1500 \mathrm{ml}$ water. Disappearance over the isolated loop is presented on a per $\mathrm{m}$ jejunum basis.

Cumulative recovery of digesta, DM, starch, PEG and xylose from the first cannula $\left(\mathbf{R}_{t_{1}}\right)$ was calculated as

$$
\mathbf{R}_{t_{1}}=\Sigma \text { collected }_{t_{0-1}} \text { /intake, }
$$

where $\Sigma$ collected $d_{t_{0-1}}$ is the amount collected from feeding $\left(t_{0}\right)$ to time $t_{\mathrm{i}}$.

Mouth-to-jejunum transit was expressed as mean transit time (MTT):

$$
\text { MTT }=\frac{\sum_{\mathbf{i}=0}^{n} \mathbf{M}_{t_{\mathbf{i}}} \times t_{\mathbf{i}}}{\sum_{\mathbf{i}=\mathbf{0}}^{n} \mathbf{M}_{t_{1}}},
$$

where $\mathrm{M}_{t_{1}}$ is the amount collected in the ith period of collection at time $t_{\mathrm{i}}$ postprandial. $t$ $=0$ was the time of feeding and $t_{1}$ is the midpoint of the collection period. 
Apparent disappearance of nutrients per $m$ intestine (AD) in the isolated loop was calculated as the difference in amount collected before and after perfusion of the loop and corrected for sampling and length of the loop (m).

$$
\mathrm{AD}=\frac{\Sigma \mathbf{M}_{\mathbf{a}}-\Sigma \mathbf{M}_{\mathbf{b}}}{4}
$$

where $\Sigma \mathbf{M}_{\mathrm{a}}$ is the total amount of component collected from first cannula corrected for sampling, $\Sigma \mathbf{M}_{\mathrm{b}}$ is the total amount collected from the second cannula after rinsing the loop, and 4 is the length of loop.

Recovery ( $R$ ) of nutrients and markers from the isolated loop was calculated as

$$
\mathrm{R}=1-\frac{\Sigma \mathrm{M}_{\mathrm{a}}-\Sigma \mathrm{M}_{\mathrm{b}}}{\Sigma \mathrm{M}_{\mathrm{a}} \times 4} \text {. }
$$

Apparent absorption (AA) corrected for losses with marker was then calculated as

$$
\mathrm{AA}=\left(1-\frac{\mathrm{R}_{\text {component }}}{\mathrm{R}_{\text {marker }}}\right) \times \Sigma \mathrm{M}_{2} .
$$

Values from the first and second day of collection on each diet were averaged before statistical analysis as no significant difference between days was identified.

Analysis of variance was performed on a computed ANOVA program (SuperANOVA, Abacus concepts, Berkeley, CA, USA) by the model:

$$
X_{i j k}=\mu+\alpha_{i}+\beta_{j}+\gamma_{k}+\epsilon_{i j k}
$$

where $\mu$ is the overall mean, $\alpha_{i}$ is the effect of diet, $\beta_{j}$ the effect of period, $\gamma_{k}$ the effect of animal and $\epsilon_{i j k}$ is a normally distributed random variable. Differences between parameters were estimated by pairwise comparison in the Student-Newman-Keuls test (Snedecor \& Cochran, 1973).

Linear regression analysis was performed testing that $\beta=0$ in the model:

$$
Y_{i}=\alpha+\beta \mathrm{x}_{i}+\epsilon_{i},
$$

where $\alpha$ is the intercept on the $Y$-axis, $\beta$ is the slope and $\epsilon_{i}$ is a random normally distributed variable (Snedecor \& Cochran, 1973).

\section{RESULTS}

Flow from the first jejunal cannula

The adjusted average intake of feed and water was 500 and $1500 \mathrm{~g}$ respectively, giving a total of $2000 \mathrm{~g}$ liquid feed per meal.

Digesta. There was a significant difference between diets in the total amounts of digesta collected from the first cannula $(P=0.0153)$. The total output of digesta over a $7.5 \mathrm{~h}$ collection period was $3797 \mathrm{~g}(1.90 \times$ intake of feed and water) with diet WF and $3712 \mathrm{~g}$ $(1.86 \times$ intake) with diet $O F$, which was significantly less than the $5046 \mathrm{~g}$ collected with diet RO and $5182 \mathrm{~g}$ for diet $\mathrm{OB}$, corresponding to 2.52 and 2.59 times the amount of feed and water ingested respectively (Fig. 2(a)). There was a rapid flow of digesta in the first hour after feeding. When feeding diets WF, RO and OB approximately $900 \mathrm{~g}$ was collected $1 \mathrm{~h}$ postprandial. In comparison, $1190 \mathrm{~g}$ was collected with diet $\mathrm{OF}$ within $30 \mathrm{~min}$ after feeding and $1834 \mathrm{~g}$ after $1 \mathrm{~h}$. The initial rapid flow with diet $O F$ was followed by a decrease in flow to almost zero for $2 \mathrm{~h}$. At $3 \mathrm{~h}$ postprandial the output increased again to the same level as for diet WF. 


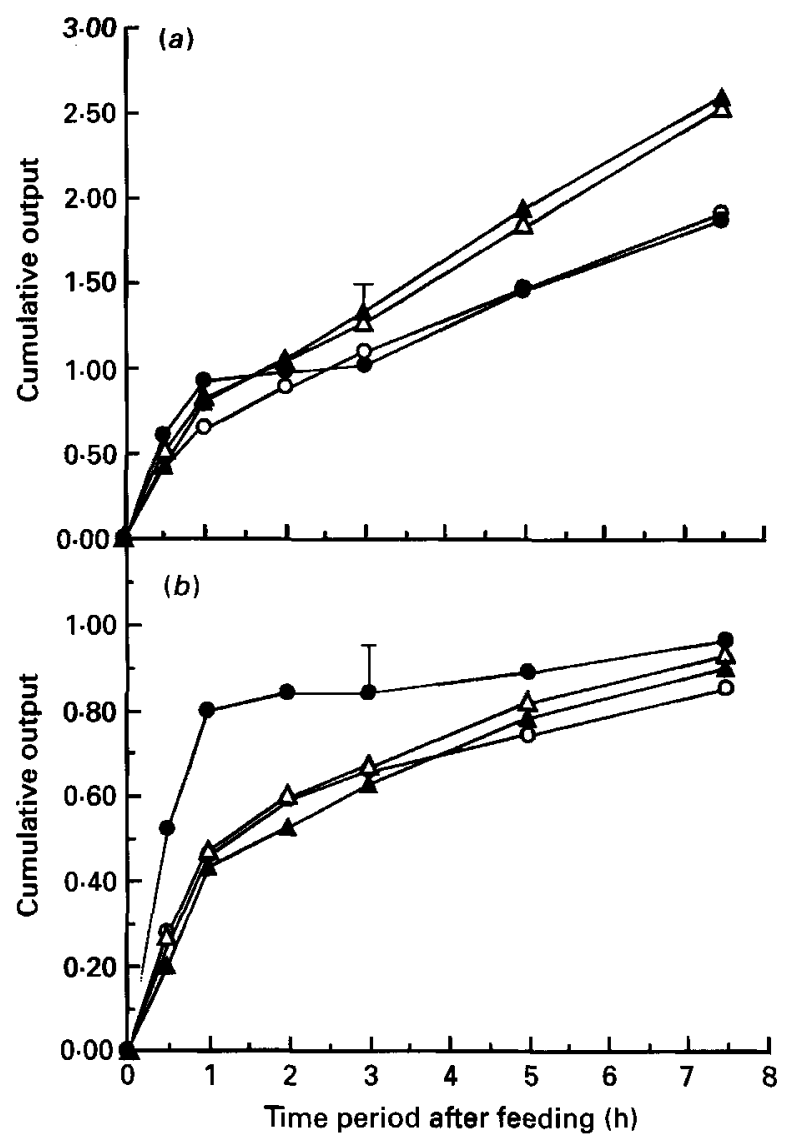

Fig. 2. Cumulative output 0-7.5 h postprandial from the first re-entrant cannula of $(a)$ digesta as a proportion of ingested feed and water and $(b)$ starch as a proportion of intake when feeding wheat- and oats-based diets to pigs: $(O)$, wheat flour; $(\mathbf{O})$, oat flour; $(\triangle)$, rolled oats; $(\boldsymbol{\Lambda})$, oat bran (for details of diets and procedures, see Table 1 and pp. 300-303). Points are means with their standard error represented by vertical bars for four pigs.

$D M$. The different digesta flow pattern of diet OF was even more pronounced for DM, starch, xylose and total nNSP. These components had similar flow patterns as illustrated in Fig. 2(b) for starch. MTT of DM (Table 2) was significantly shorter for diet OF than for all the other diets $(P=0.0013)$, which was due to a much more rapid flow within the first $2 \mathrm{~h}$ postprandial. The amount collected after $0.5 \mathrm{~h}$ was $252 \mathrm{~g}$, corresponding to $0.50 \mathrm{of}$ intake compared with $0.22-0.28$ for the other diets $(P=0.0061)$. After $3 \mathrm{~h}$, differences between diets levelled out resulting in total cumulative recoveries of $0.93-1.03$ with no significant differences between diets, although diet WF tended to give the lowest total recovery.

Starch. On average 0.91 of ingested starch was collected from the first cannula during the $7.5 \mathrm{~h}$ collection period (Fig. $1(b)$ ). The recoveries from diets WF and OB were 0.85 and 0.90 compared with 0.96 and 0.93 for diets $O F$ and RO respectively. Diet OF had a significantly different flow pattern from that of the other diets. After $0.5 \mathrm{~h}, 0.52$ of ingested starch was collected from diet OF, whereas the other diets resulted in a recovery of only $0.20-0.28(P$ $=0.0054)$. After $1 \mathrm{~h}$ the recovery from diet $\mathrm{OF}$ was 0.80 whereas the other diets resulted in a recovery of $0.45(P=0.0075)$. For diets WF, RO and $\mathrm{OB}$ there was a gradual increase 
Table 2. Mean transit time (MTT; min) of nutrients and marker collected from the first jejunal cannula when feeding wheat-and oats-based diets to pigs*

(Mean values for four pigs)

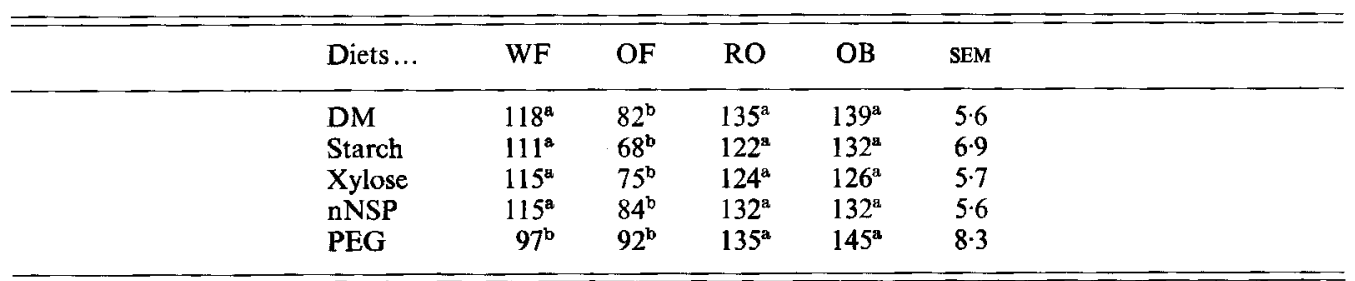

WF, wheat flour; OF, oat flour; RO, rolled oats; OB, oat bran; DM, dry matter; nNSP, neutral non-starch polysaccharides; PEG, polyethylene glycol.

a,b Values in the same row with unlike superscript letters were significantly different $(P<0-05)$.

* For details of diets and procedures, see Table 1 and pp. 300-304.

in the amount collected 1-7.5 h postprandial. Approximately half the consumed starch was collected in this period, whereas the contribution to the total amount collected was only $0 \cdot 12$ for diet $\mathrm{OF}$.

Xylose. As seen for DM and starch, dietary xylose was recovered much faster with diet OF than with the other three diets $(P=0.0020)$. The cumulative total output calculated relative to intake was: diet WF 0.77 , diet OF 0.82 , diet $R O 0.91$ and diet OB 0.99. There was a tendency for increased output of xylose with higher content of this component in the diet, diets $\mathrm{WF}$ and $\mathrm{OF}$ having significantly lower total recoveries than diets $\mathrm{RO}$ and $\mathrm{OB}$ ( $P$ $=0.0027$ ).

$n N S P$. MTT of nNSP for diets WF, RO and OB was almost equivalent to that for DM. Diet OF resulted in a significantly shorter MTT compared with those for the other diets $(P$ $=0.0027$ ). With the exception of diet OF, MTT of nNSP tended to be slightly longer than that of xylose. A total output corresponding to $0-89,1 \cdot 15,1.08$ and 1.18 of intake was found for diets WF, OF, RO and OB respectively, of which the value for diet WF was significantly lower than those for the oats-based diets $(P=0.0009)$.

$P E G$. The flow of PEG showed a rapid output of the liquid phase from the stomach when feeding diet OF. However, MTT of diets WF and OF were not significantly different. Of ingested PEG, 0.47 was recovered from the proximal cannula with diet $\mathrm{OF}, 0.24$ and 0.26 with diets WF and RO, whereas only 0.15 was recovered with diet $\mathrm{OB}$ at $0-0.5 \mathrm{~h}$ postprandial. With diets WF, RO and OB there was a gradual increase in cumulative output from the cannula $1-3 \mathrm{~h}$ postprandial, but with diet OF only 0.05 of ingested PEG was collected in this period. There were dietary differences in the total recovery of PEG after $7.5 \mathrm{~h}$ as diets OF and RO resulted in recoveries of 1.06 and 1.10 of the ingested amount respectively. This was significantly higher than the recovery of 0.73 and 0.90 obtained for diets WF and $\mathrm{OB}$ respectively; the latter diets were also significantly different from each other $(P<0.05)$.

\section{Absorption of nutrients in the isolated loop of jejunum}

The recovery of DM over the isolated loop of jejunum without correction for recovery of marker was $0.92-0.94$ with no significant differences between diets (Table 3). The recovery of marker from the loop was generally very high, but significantly higher with diet RO than with diets OF and OB for xylose $(P=0.0223)$ and total nNSP $(P=0.0206)$. Furthermore, the recovery of nNSP appeared to be higher than the recovery of xylose. There was a tendency for slightly lower recoveries of starch with higher DF content. 
Table 3. Recovery and apparent absorption of nutrients and marker from the isolated jejunal loop over an $8 \mathrm{~h}$ perfusion period when feeding wheat-and oats-based diets to pigs* (Mean values for four pigs)

\begin{tabular}{|c|c|c|c|c|c|}
\hline Diet ... & WF & OF & $\mathrm{RO}$ & OB & SEM \\
\hline \multicolumn{6}{|l|}{ Recovery } \\
\hline DM & 0.94 & 0.92 & 0.94 & 0.94 & $0-024$ \\
\hline Starch & 0.92 & 0.88 & 0.86 & 0.84 & 0.019 \\
\hline Xylose & $0.94^{\mathrm{ab}}$ & $0.86^{b}$ & $0.96^{\mathrm{a}}$ & $0.87^{b}$ & 0.018 \\
\hline nNSP & $1 \cdot 00^{\mathrm{ab}}$ & $0.98^{b}$ & $1 \cdot 04^{a}$ & $0.95^{b}$ & 0.004 \\
\hline PEG & 0.95 & 0.97 & 1.02 & 1.04 & $0 \cdot 040$ \\
\hline Starch:xylose & 0.91 & 0.86 & 0.86 & 0.82 & 0.022 \\
\hline Starch:nNSP & 0.92 & 0.87 & 0.87 & 0.83 & 0.016 \\
\hline Starch:PEG & 0.91 & 0.87 & 0.87 & 0.84 & 0.022 \\
\hline \multicolumn{6}{|c|}{ Apparent absorption ( $\mathrm{g} / \mathrm{m}$ intestine) } \\
\hline DM & $26 \cdot 8$ & $37 \cdot 1$ & $29 \cdot 1$ & $31 \cdot 7$ & $10 \cdot 81$ \\
\hline Starch & $17 \cdot 8$ & $28 \cdot 5$ & $29 \cdot 1$ & $24: 9$ & $4 \cdot 72$ \\
\hline Xylose & $0 \cdot 23^{\mathrm{b}}$ & $0.33^{\mathrm{b}}$ & $0 \cdot 15^{\mathrm{b}}$ & $1 \cdot 23^{\mathrm{a}}$ & 0.05 \\
\hline nNSP & $0 \cdot 04^{b}$ & $0 \cdot 37^{b}$ & $-0.91^{b}$ & $3 \cdot 04^{a}$ & $0 \cdot 34$ \\
\hline PEG & $0 \cdot 20$ & $0 \cdot 10$ & $-0 \cdot 15$ & -0.03 & $0 \cdot 15$ \\
\hline Starch:xylose & $19 \cdot 2$ & $33 \cdot 7$ & $30 \cdot 6$ & $28 \cdot 6$ & $5 \cdot 43$ \\
\hline Starch:nNSP & 18.0 & $29 \cdot 4$ & $28 \cdot 3$ & 26.9 & $4 \cdot 60$ \\
\hline Starch:PEG & $18 \cdot 8$ & $29 \cdot 7$ & $28 \cdot 9$ & $24 \cdot 9$ & 5.46 \\
\hline
\end{tabular}

WF, wheat flour; OF, oat flour; RO, rolled oats; OB, oat bran; DM, dry matter; nNSP, neutral non-starch polysaccharides; PEG, polyethylene glycol.

${ }_{\mathrm{a}, \mathrm{b}}$ Values in the same row with unlike superscript letters were significantly different $(P<0.05)$.

* For details of diets and procedures, see Table 1 and pp. 300-304.

Table 4. Proportion of total starch and amount of starch present as degradation products in digesta collected from the first jejunal cannula $0-0.5 \mathrm{~h}$ postprandial when feeding wheatand oats-based diets to pigs*

(Mean values for four pigs)

\begin{tabular}{|c|c|c|c|c|c|}
\hline Diet... & WF & OF & RO & OB & SEM \\
\hline \multicolumn{6}{|c|}{ Concentration (g/kg starch) } \\
\hline Glucose & $15^{\mathrm{c}}$ & $20^{\mathfrak{c}}$ & $40^{b}$ & $61^{a}$ & 5 \\
\hline Maltose & $88^{\circ}$ & $99^{c}$ & $161^{\mathrm{b}}$ & $224^{\mathrm{a}}$ & 12 \\
\hline Maltotriose & $35^{\mathrm{c}}$ & $97^{\mathrm{b}}$ & $149^{a}$ & $184^{\mathrm{a}}$ & 11 \\
\hline Total & $137^{\mathrm{c}}$ & $216^{c}$ & $351^{\mathrm{b}}$ & $468^{a}$ & 25 \\
\hline \multicolumn{6}{|l|}{ Amount $\uparrow(g)$} \\
\hline Glucose & $0 \cdot 95$ & $2 \cdot 59$ & $2 \cdot 84$ & $2 \cdot 44$ & $0 \cdot 40$ \\
\hline Maltose & $6 \cdot 29^{\mathrm{c}}$ & $13 \cdot 19^{a}$ & $11 \cdot 33^{\mathrm{ab}}$ & $9 \cdot 32^{\mathrm{b}}$ & 0.70 \\
\hline Maltotriose & $2 \cdot 45^{\mathrm{c}}$ & $13 \cdot 71^{a}$ & $10 \cdot 65^{\mathrm{ab}}$ & $7 \cdot 24^{b}$ & $1 \cdot 17$ \\
\hline Total & $9 \cdot 69^{c}$ & $29 \cdot 48^{\mathrm{a}}$ & $24 \cdot 81^{\mathrm{ab}}$ & $18 \cdot 56^{\mathrm{b}}$ & 1.98 \\
\hline
\end{tabular}

WF, wheat flour; OF, oat flour; RO, rolled oats; $O B$, oat bran.

a,b.c Values in the same row with unlike superscript letters are significantly different $(P<0.05)$.

* For details of diets and procedures, see Table 1 and pp. 300-304.

$\dagger$ Corrected for differences in amounts collected $0-0.5 \mathrm{~h}$ after feeding. 

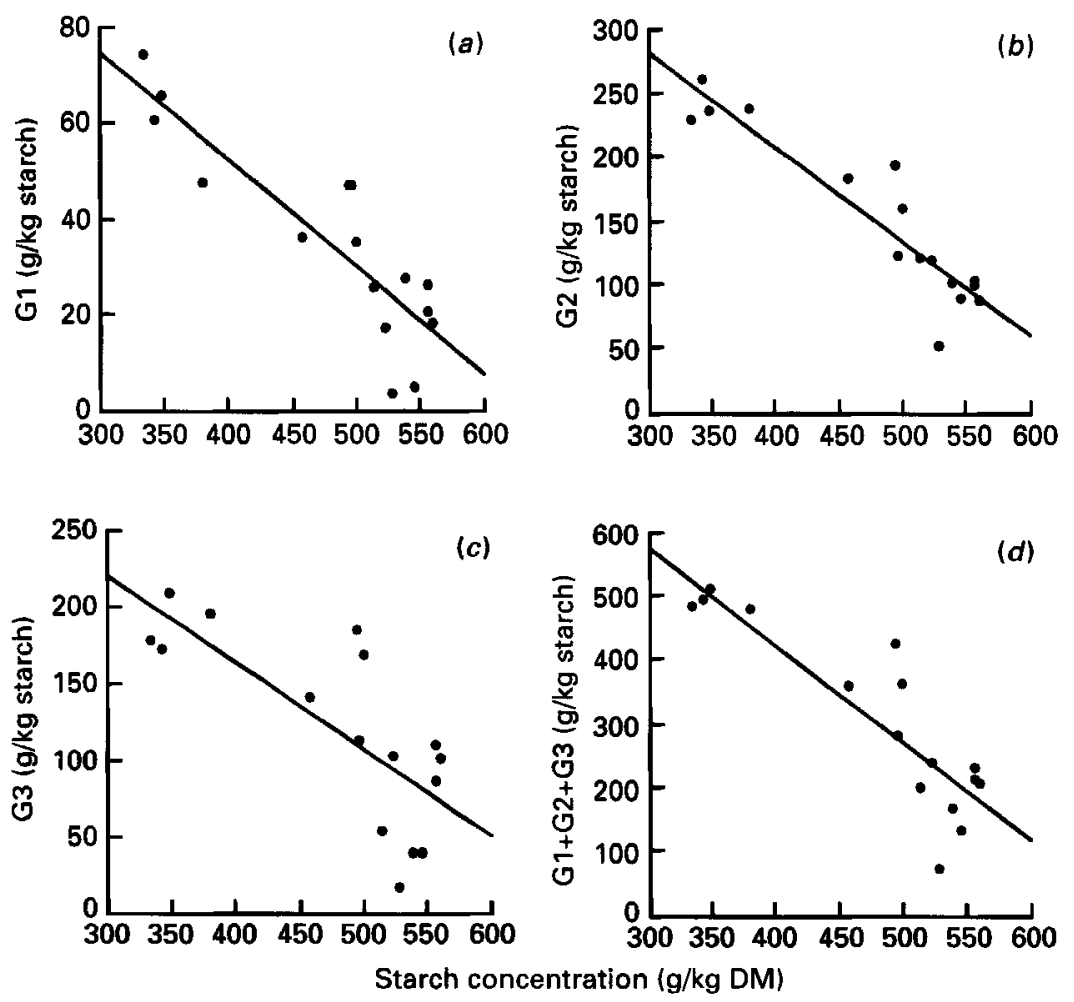

Fig. 3. Relative amounts of starch present as (a) glucose (G1), (b) maltose (G2), (c) maltotriose (G3) and (d) $\mathrm{G} 1+\mathrm{G} 2+\mathrm{G} 3 v$ concentration of starch in jejunal digesta collected before the loop $0-0.5 \mathrm{~h}$ postprandial when feeding wheat- and oat-based diets to pigs. For details of diets and procedures, see Table 1 and pp. 300-303. Linear regression were as follows $(a) Y=-2 \cdot 23 \times 10^{-4} X+0 \cdot 14, r^{2} 0 \cdot 77, P=0.0001 ;(b) Y=-7.34 \times 10^{-4} X+0.50, r^{2} 0.85$, $P=0.0010 ;(c) Y=-5.61 \times 10^{-4} X+0.39, r^{2} 0.56, P=0.0008 ;(d) Y=-1.52 \times 10^{-3} X+1.03, r^{2} 0.77, P=0.0001$.

Significance levels were $P=0.1219$ for the uncorrected recovery, $P=0.0955$ when corrected with xylose and $P=0.0636$ when starch recovery was related to the recovery of total nNSP.

No significant differences were seen in the apparent quantitative absorption of starch over the $8 \mathrm{~h}$ perfusion period. However, there was a tendency for a lower absorption in the oats-based diets with a higher content of DF and lower content of starch in the diet. Diet WF, on the other hand, showed the lowest apparent absorption of all diets.

\section{Starch degradation in the upper jejunum}

The major degradation products of starch in digesta were maltose and maltotriose, accounting for up to 224 and $184 \mathrm{~g} / \mathrm{kg}$ starch respectively, whereas glucose represented only $15-61 \mathrm{~g} / \mathrm{kg}$ (Table 4). The extent of degradation increased with higher DF and lower starch contents in the diet with the proportion of starch consisting of glucose, maltose and maltotriose ranging from $137 \mathrm{~g} / \mathrm{kg}$ starch in digesta with diet WF to $468 \mathrm{~g} / \mathrm{kg}$ when diet OB was fed.

The proportion of starch present as glucose, maltose and maltotriose and the sum of these are plotted $v$. the total concentration of starch (including amylosis products) in digesta samples collected within $0.5 \mathrm{~h}$ after feeding in Fig. $3(a-d)$. There was an inverse linear relationship between the content of starch in digesta and the amounts present as free 
glucose, maltose or maltotriose, with correlation coefficients of $r^{2} 0.77, P=0.000 \mathrm{I} ; r^{2} 0.85$, $P=0.0010$ and $r^{2} 0.56, P=0.0008$ respectively. The sum of these degradation products showed a correlation of $r^{2} 0.77, P=0.0001$, to the starch content in digesta.

When corrected for differences in flow of digesta within the first $0.5 \mathrm{~h}$ after feeding, significantly larger amounts of maltose $(P=0.0021)$ and maltotriose $(P=0.0025)$ were present in the proximal jejunum when diet OF was fed compared with diets WF and OB (Table 4). Furthermore, there was a gradual decrease in the amounts of glucose, maltose and maltotriose present when feeding oat-based diets with a higher level of DF. The amount of starch degraded in diet WF was significantly lower than that in all oats-based diets $(P=0.0019)$. The amount of glucose in digesta was similar $(2.44-2.84 \mathrm{~g})$ with all the oat-based diets whereas diet WF gave less than half the amount $(0.95 \mathrm{~g} ; P=0.0571)$. There was practically no free glucose, maltose and maltotriose in the diets, so the high concentrations found in digesta samples came from action of digestive enzymes. A very small proportion of the free glucose found in digesta samples could originate from cleavage of sucrose in the diet. The sucrose content in oat bran was highest $(29.2 \mathrm{~g} / \mathrm{kg} \mathrm{DM})$. This gave a contribution to glucose of $3.21 \%$, which was not accounted for in the analytical procedure.

\section{DISCUSSION}

The rate of gastric emptying of the dietary components as estimated from the jejunal flow from the first jejunal cannula in the present study was not related to the content of DF in a direct manner. MTT of the soluble marker was significantly higher in the two diets with the highest DF content, whereas only diet OF deviated significantly from the other diets in the emptying of DM, starch, xylose and total nNSP. These results are in agreement with those of Rainbird et al. (1984), who found that DF only affected gastric emptying of digesta, but not DM and glucose, with semi-synthetic low-DF diets containing different sources and quantities of isolated DF. There was a very rapid duodenal flow with diet OF which could be due to a high proportion of very fine particles in this diet. Oat bran, on the other hand, consisted of very large particles of which less than $35 \%$ passed through a $500 \mu \mathrm{m}$ sieve. It is possible that the fine structure of the oat-flour diet resulted in a liquid-meal behaviour of gastric emptying, whereas the more coarse particles of the other diets had an emptying behaviour more like a solid meal. Consequently, although gastric emptying seemed to be affected by the DF content in the diet, other factors such as the particle size and physical structure of the diet had a major impact on the rate of gastric emptying of these diets. The present findings on stomach output are in general agreement with results from Cuber \& Laplace (1979), who fed a semi-purified diet to re-entrant-cannulated pigs after a $24 \mathrm{~h}$ fasting period. Similar transit times have also been found in more complex maize- and barley-based diets (Laplace \& Tomassone, 1970; Holmes et al. 1974). The estimated rate of gastric emptying in this study, on the other hand, was generally shorter than in experiments performed with gastric-cannulated pigs fed on a semi-purified low-DF diet supplemented with various fibre sources (Rainbird \& Low, 1986a, $b$ ). The discrepancy is presumably an effect of different cannulation techniques. This is in agreement with previous reports showing that cannulation in the duodenum leads to estimates of a more rapid flow in the first $2 \mathrm{~h}$ after feeding than when fitting pig with a gastric cannula, whereas the latter leads to a more rapid flow 4-7 h after feeding (Cuber et al. 1980).

There was a net secretion of endogenous material of $1700-3200 \mathrm{~g}$ in the $7.5 \mathrm{~h}$ collection period. Although the endogenous secretion seemed to be stimulated more by diets with a higher level of DF the quantities were not related directly to the DF content. No significant differences were seen between diets RO and OB even though there was twice as much nNSP in the latter, while digesta output was significantly higher when feeding these diets 
compared with diets WF and OF. In agreement with the present observations, Zebrowska et al. (1983) found that $81 \%$ more pancreatic juice was secreted when feeding $200 \mathrm{~g}$ $\mathrm{NSP} / \mathrm{kg}$ diet compared with $50 \mathrm{~g} \mathrm{NSP} / \mathrm{kg}$. Zebrowska \& Low (1987) found concordantly that NSP stimulated pancreatic secretion much more than the starch fraction.

Due to the high level of secretion from the stomach, bile duct and pancreas and of absorption of nutrients before the first re-entrant cannula (Zebrowska et al. 1983), gastric emptying rates by means of the flow from the first re-entrant cannula are estimated best by use of non-absorbable markers. Xylose was chosen as the internal dietary marker in the present study because xylose from the cell walls, as long as it is present in intact arabinoxylan polysaccharides, is neither absorbed nor secreted from the upper gastrointestinal tract. The superiority of a dietary component as a solid-phase marker over external markers such as $\mathrm{Cr}_{2} \mathrm{O}_{3}$ is the elimination of the risk of the external markers not truly representing flow pattern of the dietary components (Warner, 1981). Total nNSP as an internal marker should be used with some caution, since endogenous secretions, sloughed epithelial cells and microbial carbohydrates contribute to the amount of certain monosaccharides (McAllen, 1985). There were, however, differences in the amounts of dietary and liquid-phase markers recovered from the first cannula. On the other hand, these differences were not related to the rather small but significant differences in the recovery of markers during perfusion. A disadvantage of using xylose as an internal marker in the present study was that the content was rather low and varied between diets.

A decrease in absorption rate of starch from diets containing soluble DF by means of a shift or extension of the site of absorption towards the more distal part of the small intestine has been suggested by Jenkins et al. (1987) as the main factor in controlling the glycaemic response. If this is so, the experimental diets of the present study would be expected to result in different recoveries of glucose when perfusing digesta through the isolated loop of jejunum. However, the apparent absorption of glucose over an $8 \mathrm{~h}$ perfusion period did not vary significantly between diets in spite of a four times higher content of soluble DF and a $30 \%$ lower content of starch in diet OB compared with diet WF. On the contrary, the relative recovery of starch tended to decrease with a higher dietary level of DF and lower content of starch in the diet. Rérat et al. (1984) showed that a relatively smaller amount of glucose appeared in the portal blood with increasing amounts of ingested maize starch and suggested that the enzymic hydrolysis rate accounted for this. This was supported by a higher proportion of the starch present as malto-oligosaccharides in digesta collected within the first $0.5 \mathrm{~h}$ after feeding diets with a higher DF and lower starch content in the present study. Bach Knudsen et al. (1993) found a digestibility in the proximal third of the small intestine of an oat-flour-based diet of 0.64 compared with 0.49 for an oat-bran-based diet. In the middle third the digestibility was 0.95 and 0.90 respectively (Bach Knudsen $e t$ al. 1993). Furthermore, Keys \& DeBarthe (1974) estimated the digestibility of starch from wheat and barley diets fed to pigs fitted with duodenal cannulas to be 0.76 and 0.45 respectively. The apparent high recovery from the isolated loop of jejunum in the present study must be seen in terms of the length of the isolated loop, which represents less than $10 \%$ of the entire small intestine of the pig. Extending the loop to a length corresponding to one-third of the small intestine would, with the assumption of uniform absorption rates, result in digestibilities equivalent to those obtained by Bach Knudsen et al. (1993) and Keys $\&$ DeBarthe (1974). The net absorption of glucose from starch was $17 \cdot 8-29 \cdot 1 \mathrm{~g} / \mathrm{m}$ intestine in the $8 \mathrm{~h}$ perfusion period corresponding to $2 \cdot 2-3 \cdot 6 \mathrm{~g} / \mathrm{m}$ per $\mathrm{h}$. Values found by Rainbird et al. (1984) and Low et al. (1986) for perfusion of glucose solutions (20 g/l) at a constant rate of $8 \mathrm{ml} / \mathrm{min}$ (average flow rate of digesta at this site in $8 \mathrm{~h}$ ) were 6.50 and $6.75 \mathrm{~g} / \mathrm{m}$ per $\mathrm{h}$ respectively. Addition of high-viscosity guar gum $(6.7 \mathrm{~g} / 1)$ reduced the absorption to $3.89-3.97 \mathrm{~g} / \mathrm{m}$ per $\mathrm{h}$ (Rainbird et al. 1984; Low et al. 1986), whereas addition of wheat 
bran, low-viscosity guar gum, pectin and cellulose, in decreasing order of efficacy, decreased the absorption to $3.41-5.48 \mathrm{~g} / \mathrm{m}$ per h (Low et al. 1986). The smaller amount of glucose absorbed in the present study in comparison with the studies of Rainbird et al. (1984) and Low et al. (1986) could be a consequence of an initial larger load of carbohydrate that had to be degraded by $\alpha$-amylase before absorption. In that case both degradation and absorption would be rate-limiting factors. Artificially high flow-rates introduced by open cannulas could limit the time of exposure of brush-border enzymes to the substrates and thereby the amount of glucose absorbed. However, studies in both rats and pigs indicate a generally very rapid flow in the proximal intestine (Brown et al. 1988; Clemens et al. 1975), suggesting that the rate of passage might not be the limiting factor. A study by Anderson et al. (1989) demonstrated that gut motility creating radial convection is essential for an attenuating affect of guar gum on glucose absorption in the rat intestine, whereas in studies with laparotomized anaesthetized rats the flow is laminar. Surgical intervention of the small intestine by transection and cannulation of the jejunum may lead to disturbed gastrointestinal motility but does presumably not lead to laminar flow during perfusion in the conscious pig. It has previously been demonstrated that the motility distal to re-entrant cannulas is absent immediately after surgery but that the myoelectric migrating complex is reorganized a few days after, although at a different timing (Laplace, 1980).

The extensive degradation indicates that the activity of pancreatic enzymes was not inhibited by the DF in these diets, but that the amount of substrate in the bulk of digesta appearing in the duodenum immediately after feeding may have exceeded the capacity of the pancreatic enzymes to degrade the starch, thereby making it available for absorption. Alternatively, DF may inhibit the activity of the mucosal enzymes, thereby leading to accumulation of endproducts of pancreatic $\alpha$-amylase digestion. This theory has been rejected by Rainbird et al. (1984) who found no difference in the absorption rate of glucose and maltose. Furthermore, Mathers et al. (1992) found that guar gum had no effect of the maltase $(E C 3.2 .1 .20)$ activity in the proximal and distal small intestine of rats. The small degree of starch degradation in digesta when the pigs were fed on the wheat-flour-based diet (WF) in comparison with oats-based diets might be due to differences in the susceptibility of starch for $\alpha$-amylase digestion. The former was fed unprocessed (raw starch) while all the oats products had been steam-treated, which could lead to some gelatinization of the starch thereby increasing the $\alpha$-amylase susceptibility of the latter.

Breakdown, absorption and transport of carbohydrates in the intestine is a dynamic system. Therefore, too much emphasis should not be put to the absolute values of degradation products in digesta as some of the readily absorbable starch hydrolysis products may already have been absorbed proximal to the first re-entrant cannula. However, estimates of the quantities available for absorption $0-0.5 \mathrm{~h}$ postprandial correlated very well with the glycaemic response to similar diets in pigs fitted with catheters in the jugular vein (K. E. Bach Knudsen, unpublished results). Furthermore, this corresponded to the ranking of estimated gastric emptying suggesting that the rate of absorption on site induced by differences in gastric emptying, and thereby delivery of digestible carbohydrates to the small intestine, is of major importance with this type of diet.

\section{Conclusion}

The present study showed that diets based on wheat and oats did not affect gastric emptying in re-entrant-cannulated pigs in a simple manner related to the dietary level of soluble DF. Other factors such as particle size, physical structure, starch availability, solubility of cell-wall polysaccharide and interaction between dietary components may interfere with any effect of DF in complex diets. The apparent quantitative absorption of 
starch in the upper jejunum over an $8 \mathrm{~h}$ perfusion period was not affected by the DF content of the diet while the relative recovery of starch from the isolated loop was inversely related to the dietary level of starch. This suggests that delayed absorption leading to a lower glycaemic response to cereal-based diets naturally rich in soluble DF may not be induced by an impaired absorption in the proximal intestine where capacity to absorb the large quantities of digestible carbohydrate delivered to the duodenum appear rate-limiting. Although kinetics of absorption in the jejunal loop were not studied in the present experiment, the ranking of MTT and calculated amounts of malto-oligosaccharides present in jejunal digesta immediately after the meal suggests that gastric emptying is a major factor controlling the glycaemic response to these cereal-based diets.

This work was supported by the Danish Agricultural and Veterinary Research Council and the Danish Research Academy. The authors are indebted to Dr Teresa Zebrowska and Dr Graham Low for excellent technical advice in setting up the cannulation and collection technique, Dr Peter J. Wood and John Weisz for using facilities and technical advice in HPLC analysis. They would like to thank Dr Henry Jørgensen for carrying out surgery, Henning Laursen, Karl Henrik Jakobsen, Hanne Lund Jensen, Jytte Balle and Lone Rasmussen for technical assistance and Dr Bjørn O. Eggum and Dr Brittmarie Sandström for their advice during the work.

\section{REFERENCES}

Anderson, B. W., Kneip, J. M., Levine, A. S. \& Levitt, M. D. (1989). Influence of infusate viscosity on intestinal absorption in the rat. An explanation of previous discrepant results. Gastroenterology 97, 938-943.

Association of Official Analytical Chemists (1975). Official Methods of Analysis, 11th ed., Washington, DC: Association of Official Analytical Chemists.

Bach Knudsen, K. E., Jensen, B. B. \& Hansen, I. (1993). Digestion of polysaccharides and other major components in the small and large intestine of pigs fed diets consisting of oat fractions rich in $\beta$-D-glucan. British Journal of Nutrition 70, 537-555.

Blackburn, N. A. \& Johnson, I. T. (1983). The influence of guar gum on the movements of inulin, glucose and fluid in rat intestine during perfusion in vivo. Pflügers Archiv 397, 144-148.

Brown, N. J., Worlding, J., Rumsey, R. D. E. \& Read, N. W. (1988). The effect of guar gum on the distribution of a radiolabelled meal in the gastrointestinal tract of the rat. British Journal of Nutrition 59, 223-231.

Chen, W. J. L. \& Anderson, J. W. (1986). Hypocholesterolemic effects of soluble fibers. In Dietary Fiber. Basic and Clinical Aspects, pp. 275-285 [G. V. Vahouny and D. Kritchevsky, editors]. New York: Plenum Press.

Clemens, E. T., Stevens, C. E. \& Southworth, M. (1975). Sites of organic acid production and pattern of digesta movement in the gastrointestinal tract of swine. Journal of Nutrition 105, 759-768.

Cuber, J.-C. \& Laplace, J.-P. (1979). Evacuation gastrique de la matière sèche d'un régime semi-purifié à base d'amidon de maîs chez le porc (Gastric emptying of maize starch dry matter in pigs given a semi-purified diet). Annales de Biologie Animale Biochimie Biophysique 19, 899-905.

Cuber, J. C., Laplace, J. P. \& Villiers, P. A. (1980). Fistulation de l'estomac et contenus gastriques résiduels après ingestion d'un régime semi-purifié à base d'amidon de maïs chez le porc (Fistulation of the stomach and residual gastric contents after intake of a semi-purified maize diet by pigs). Reproduction Nutrition Développement 20, $1161-1172$.

Holmes, J. H. G., Bailey, H. S. \& Horney, F. D. (1974). Digestion of dry and high moisture maize diets in the stomach of the pig. British Journal of Nutrition 32, 639-646.

Horszczaruk, F., Buraczewska, L. \& Buraczewski, S. (1974). Ilość i sktad soku jelitowego wydzielanego do izolowanej pętli jelita cienkigo u świń (Amount and composition of intestinal juice collected from isolated intestinal loops of pigs). Roczniki nauk Rolniczych 95, 69-77.

Hyden, S. (1955). A turbidimetric method for the determination of high polyethylene glycols in biological materials. Kungliga Lantbrukshögskolans Annaler 22, 139-145.

Jenkins, D. J. A., Jenkins, A. L., Wolever, T. M. S., Collier, G. R., Rao, A. V. \& Thompson, L. U. (1987). Starchy foods and fiber: reduced rate of digestion and improved carbohydrate metabolism. Scandinavian Journal of Gastroenterology 22, 132-141.

Keys, J. E. \& DeBarthe, J. V. (1974). Site and extent of carbohydrate, dry matter, energy and protein digestion and the rate of passage of grain diets in swine. Journal of Animal Science 39, 57-62.

Laplace, J. P. (1980). Stomach and small intestinal motility in the pig: electromyography in nutritional studies. In Current Concepts of Digestion and Absorption in Pigs. NIRD Technical Bulletin no. 3, pp. 24-31 [A. G. Low and I. G. Partridge, editors]. Reading: National Institute for Research in Dairying. 
Laplace, J. P. \& Tomassone, R. (1970). Evacuation gastro-duodénale chez le porc et influence de l'alimentation (Gastro-duodenal emptying in the pig. Chronic fistulation through extra-pleural thoracic pathway; study of a technique for mathematical analysis of the emptying). Annales de Zootechnique 19, 303-332.

Low, A. G., Zebrowska, T., Heppell, L. M. J. \& Smith, H. A. (1986). Influence of wheat bran, cellulose, pectin and low or high viscosity guar gum on glucose and water absorption from pig jejunum. Proceedings of the Nutrition Society 45, 55A.

Lund, E. K., Gee, J. M., Brown, J. C., Wood, P. J. \& Johnson, I. T. (1989). Effects of oat gum on the physical properties of the gastrointestinal contents and on the uptake of D-galactose and cholesterol by rat small intestine in vitro. British Journal of Nutrition 62, 91-101.

McAllen, A. B. (1985). Analysis of carbohydrate in the alimentary tract and its nutritional significance. In Analysis of Food Carbohydrate, pp. 269-297 [G. G. Birch, editor]. New York: Elsevier Science Publishing Co., Inc.

McCleary, B. V. \& Glennie-Holmes, M. (1985). Enzymatic quantification of $(1 \rightarrow 3)(1 \rightarrow 4)-\beta-D-$ glucan in barley and malt. Journal of the Institute of Brewing 91, 285-295.

Mathers, J. C., Lawlor, P. A. \& Parker, D. S. (1992). Effects of guar gum supplementation of breakfast cereals on small intestinal hydrolases in the rat. Proceedings of the Nutrition Society 51, 2A.

Rainbird, A. L. \& Low, A. G. (1986a). Effect of guar gum on gastric emptying in growing pigs. British Journal of Nutrition 55, 87-98.

Rainbird, A. L. \& Low, A. G. (1986b). Effect of various types of dietary fibre on gastric emptying in growing pigs. British Journal of Nutrition 55, 111-121.

Rainbird, A. L., Low, A. G. \& Zebrowska, T. (1984). Effect of guar gum on glucose and water absorption from isolated loop of jejunum in conscious growing pigs. British Journal of Nutrition 52, 489-498.

Rérat, A. A., Vaissade, P. \& Vaugelade, P. (1984). Absorption kinetics of some carbohydrates in conscious pigs. 2. Quantitative aspects. British Journal of Nutrition 51, 517-529.

Roberts, F. G., Low, A. G., Young, S., Smith, H. A. \& Ellis, P. R. (1991). The effect of high viscosity guar gum flour on the rate of glucose absorption and net insulin production in the portal blood of the pig. Proceedings of the Nutrition Society 50,72A.

Snedecor, G. W. \& Cochran, W. G. (1973). Statistical Methods, 6th ed. Ames, Iowa: Iowa State University Press.

Stoldt, W. (1952). Verslag zur Vereinheitlichung der Fettbestimmung in Lebensmitteln (Suggestions for the standardization of the determination of fat in foodstuffs). Fette, Seifen, Anstrichmittel 54, 206-207.

Warner, A. C. I. (1981). Rate of passage of digesta through the gut of mammals and birds. Nutrition Abstracts and Reviews Series B 51, 789-820.

Wood, P. J., Braaten, J. T., Scott, F. W., Riedel, D. \& Poste, L. M. (1990). Comparisons of viscous properties of oat and guar gum and the effects of these and oat bran on glycemic index. Journal of Agricultural and Food Chemistry 38, 753-757.

Wood, P. J. \& Fulcher, R. G. (1978). Interaction of some dyes with cereal $\beta$-glucans. Cereal Chemistry 55, 952-966.

Zebrowska, T. \& Low, A. G. (1987). The influence of diets based on whole wheat, wheat flour and wheat bran on exocrine pancreatic secretion in pigs. Journal of Nutrition 117, 1212-1216.

Zebrowska, T., Low, A. G. \& Zebrowska, H. (1983). Studies on gastric digestion of protein and carbohydrate, gastric secretion and exocrine pancreatic secretion in the growing pig. British Journal of Nutrition 49, 401-410. 